\title{
HUBUNGAN POLA ASUH IBU DENGAN KEJADIAN STUNTING PADA ANAK USIA 12 - 24 Bulan DI WILAYAH KERJA PUSKESMAS PACCELLEKANG KABUPATEN GOWA
}

\author{
Hamdayani, Sainah, Sri Mawarni \\ Program Studi Ilmu Keperawatan, Universitas Patria Artha \\ *E-mail: nershamdayani@gmail.com
}

\author{
Patria Artha Journal of Nursing Science \\ 2021. Vol. 5(1), 33 - 40 \\ Issn: 25495674 \\ e-issn: 25497545 \\ Reprints and permission: \\ http://ejournal.patria-artha.ac.id/index.php/jns
}

\begin{abstract}
Abstrak
Tujuan: Penelitian ini bertujuan Untuk menganalisis secara mendalam hubungan antara untuk mengetahui Hubungan Pola Asuh Ibu dengan Kejadian Stunting pada Anak usia 12 - 24 Bulan Di Wilayah Kerja Puskesmas Paccellekang Kabupaten Gowa. Metode Penelitian: Jenis penelitian kuantitatif dengan rancangan penelitian analitik korelasi dengan pendekatan desain Cross Sectional Study. Populasi dalam penelitian ini sebanyak 153 orang, Sampel dalam penelitian ini sebanyak $61 \mathrm{r}$ hasil penelitian ini menunjukkan ada hubungan antara Pola Asuh Ibu dengan Kejadian Stunting pada esponden dengan teknik pengambilan sampel menggunakan non random sampling. Hasil: Setelah dilakukan analisa dan interpretasi data diperoleh Ada hubungan Pola Asuh Ibu dengan Kejadian Stunting pada Anak usia 12 - 24 Bulan Di Wilayah Kerja Puskesmas Paccellekang Kabupaten Gowa dengan nilai $\rho$ 0,000 $<0,005$. Penelitian ini menunjukkan ada hubungan antara Pola Asuh Ibu dengan Kejadian Stunting pada Anak 12 - 24 Bulan Di Wilayah Kerja Puskesmas Paccellekang Kabupaten Gowa.

Implikasi penelitian bahwa masih ada beberapa responden yang mengalami kejadian stunting karena pola asuh ibu yang kurang baik Rekomendasi: perlu adanya peran keluarga terutama ibu dalam memberikan pola asuh yang baik agar mencegah kejadian stunting pada anak.
\end{abstract}

Kata kunci: Stunting,Pola Asuh Ibu.

Stunting merupakan bentuk dari proses pertumbuhan yang terhambat, dan merupakan salah satu masalah gizi yang perlu mendapat perhatian (Picauly dan Toy, 2015). Masalah pendek (stunting) pada anak akan menghambat perkembangan, dampak negatif ini akan berlanjut dalam kehidupan setelahnya. Hal ini karena sekitar $70 \%$ pembentukan sel otak terjadi sejak janin masih dalam kandungan hingga anak berumur 2 tahun. Jika otak mengalami gangguan pertumbuhan maka jumlah sel otak, serabut sel dan penghubung sel otak akan berkurang. Hal ini menyebabkan penurunan intelegensia, bila mencari pekerjaan maka peluang gagal tes wawancara menjadi lebih besar, tidak mendapat pekerjaaan yang baik dan akan menyebabkan penghasilan yang rendah serta tidak dapat mencukupi kebutuhan pangan. Selain itu, dari aspek estetika, anak yang tumbuh proporsional akan kelihatan lebih menarik dari anak yang pendek (Depkes, 2015). Stunting merupakan indikator keberhasilan, kesejahteraan, pendidikan dan pendapatan masyarakat (Depkes, 2015). Faktor asupan makanan, pola asuh dan kesehatan yang diperoleh ibu dan anakanaknya memiliki dampak besar bagi kesehatan dan kesejahteraan mereka di masa mendatang (Bappenas, 2016). Stunting memiliki dampak yang sangat luas mulai dari sisi ekonomi, kecerdasan, dan kualitas yang berpengaruh terhadap masa 
depan anak. Studi yang telah dilakukan menunjukkan bahwa anak yang pendek sangat erat hubungannya dengan prestasi di sekolah yang buruk. Anak-anak yang pendek memiliki risiko yang lebih besar untuk tumbuh menjadi orang dewasa yang kurang berpendidikan, miskin, kurang sehat dan lebih rentan terhadap penyakit tidak menular (Unicef Indonesia, 2015).

Masalah gizi khususnya stunting pada balita disebabkan asupan makan yang kurang memadai dan penyakit yang merupakan penyebab langsung masalah gizi pada anak. Keadaan tersebut terjadi karena praktik pemberian makan yang tidak tepat, penyakit infeksi yang berulang, perilaku kebersihan dan pengasuhan yang buruk. Pada intinya, semua ini disebabkan karena faktor kurangnya pendidikan dan pengetahuan pengasuhan anak, penggunaan air yang tidak bersih, lingkungan yang tidak sehat, pendapatan yang rendah dan keterbatasan akses terhadap pangan (Unicef Indonesia, 2015).

Berdasarkan data dunia terdapat 162 juta anak balita usia dibawah 5 tahun terancam dan beresiko mengalami stunting, WHO memperkirakan jika stunting terus berlanjut maka pada tahun 2025 diproyeksikan akan ada 127 juta anak balita akan mengalami stunting. Di Asia sendiri terdapat $56 \%$ anak dan di Afrika 36\% anak (Kemenkes RI, 2016). Prevalensi balita stunting di Asia posisi tertinggi diduduki oleh negara Indonesia $(36,4 \%)$ dibandingkan dengan dengan negara Asia lainnya seperti Myanmar (29,2\%), Viet Nam (24,6\%), Brunei Darussalam (19,7\%), Malaysia $(17,7 \%)$, Thailand $(16,3 \%)$ dan Singapura $(4,4 \%)$ (United Nations, 2017). Angka balita pendek di Indonesia masih tinggi dan merupakan masalah kesehatan yang harus ditanggulangi. Pertumbuhan tidak maksimal diderita oleh sekitar 8,9 juta anak Indonesia, atau satu dari tiga anak Indonesia (Millennium Challenge Account, 2014). Global Nutrition Report tahun 2014 menunjukkan Indonesia termasuk dalam 17 negara, di antara 117 negara, yang mempunyai tiga masalah gizi yaitu stunting, wasting dan over weight pada balita (Kemenkes RI, 2016).
Status stunting berdasarkan provinsi tahun 2017 di Kalimantan Barat termasuk ke dalam 10 provinsi tertinggi terjadinya stunting yaitu terdapat 36,5\% (Kemenkes RI, 2018). Secara nasional prevalensi pendek pada tahun 2013 mencapai 37.2\%. Angka ini lebih besar dari tahun 2010 sebesar 35.6\% dan tahun 2007 sebesar $36.8 \%$. Di Provinsi Banten, pada tahun 2007, 2010 dan 2013 prevalensi stunting masih berada diatas 30\% (Depkes, 2013). Sementara itu berdasarkan Riskesdas Provinsi Banten tahun 2007, di Kota Tangerang prevalensi stunting sebesar 30.1\% (Depkes, 2007). Jika dibandingkan dengan batas non public health problem yang ditetapkan WHO untuk masalah kependekan sebesar 20\%, maka Kota Tangerang masih dalam kondisi bermasalah kesehatan masyarakat (Depkes, 2015).

Menurut Riskesdas (2018) prevalensi di Provinsi Sulawesi Selatan untuk kategori sangat pendek $15,8 \%$ dan pendek $23,1 \%$, sehingga prevalensi Stunting di Sulawesi Selatan yaitu 38,9\%. Sedangkan menurut Riskesdas (2018) prevalensi stunting di Sulawesi Selatan yaitu sekitar $41 \%$. Masalah kesehatan masyarakat dianggap berat bila prevalensi pendek sebesar 30$39 \%$ dan serius bila prevalensi pendek $\geq$ 40\% . (Riskesdas 2018). Masalah stunting di Sulawesi Selatan ini merupakan masalah yang sangat serius.

Di Kota Makassar prevalensi stunting pada tahun 2017 sebanyak 26,9\% (sangat pendek yaitu $16,8 \%$ dan pendek $10,1 \%)$. Sementara batas Non Public Health Problem yang ditolerir oleh Badan Kesehatan Dunia untuk kejadian stunting hanya 20\% atau seperlima dari jumlah total balita di suatu Negara (Riskesdas, 2018).

Berdasarkan studi pendahuluan yang di lakukan oleh peneliti pada tanggal 12 Desember di Puskesmas Paccellekang Kabupaten Gowa, didapatkan balita dengan kasus gizi kurang pada bulan Agustus 2019 sebanyak 128 balita dan kasus gizi buruk sebanyak 25 dari 935 jumlah balita. Yang paling banyak kejadian gizi buruk dan gizi kurang berada di 3 posyandu yang terletak diwilayah Puskesmas Paccellekang yaitu Posyandu Dusun Macinna, Posyandu Dusun Baddo- 
Baddo, dan Posyandu Dusun Embung di Desa Je'nemadinging. Namun yang paling tinggi terletak di posyandu Dusun Embung dengan kejadian gizi kurang sebanyak 10 orang dan gizi buruk sebanyak 6 orang.

Kejadian stunting pada balita meningkat seiring bertambahnya usia. Berdasarkan penelitian Rahmayana (2015) Prevalensi stunting dan severe stunting lebih tinggi pada anak usia $24-59$ bulan yaitu $50 \%$ dan 24\%. Temuan ini mirip dengan hasil dari Bangladesh, India dan Pakistan di mana anak-anak berusia 24-59 bulan ditemukan berada pada risiko lebih besar untuk terhambat. Hal ini menunjukkan bahwa untuk anak usia 24-59 bulan stunting tidak mungkin reversible. Pola asuh merupakan salah satu faktor yang berkaitan dengan stunting. Penelitian Picauly dan Toy (2017), menunjukkan bahwa ibu dengan pola asuh yang kurang atau rendah memiliki peluang lebih besar anaknya terkena stunting dibandingkan ibu dengan pola asuh baik. Berdasarkan penelitian Sabatmaja dkk (2016), di Lampung, Aceh, Yogyakarta, dan Papua, peranan karakteristik ibu dan pola asuh sangat berpengaruh terhadap status gizi balita. Hal ini karena, ibu yang memiliki karakteristik baik dan dapat mengelola pendapatan dengan baik, cenderung mempraktikkan pola asuh yang baik dan akhirnya akan meningkatkan status gizi balita. Terdapat asumsi bahwa semakin tinggi pendapatan maka akan meningkatkan pola asuh dan kesehatan masyarakat. Pola asuh kesehatan berhubungan langsung dengan status gizi dan pola asuh kesehatan juga berhubungan dengan status kesehatan. Artinya, pola asuh kesehatan dapat mempengaruhi status kesehatan dan status gizi (Sabatmaja dkk, 2016).

Penelitian yang dilakukan Renyoet dkk (2017) tentang hubungan pola asuh dengan kejadian stunting, menunjukkan bahwa praktik pemberian makan, rangsangan psikososial, higiene dan sanitasi lingkungan, serta pemanfaatan layanan kesehatan memiliki pengaruh yang signifikan terhadap kejadian stunting pada balita. Sementara itu, penelitian Arifin dkk (2016) tentang analisis sebaran dan penyebab stunting menunjukkan, pemberian ASI eksklusif mempunyai hubungan yang signifikan dan merupakan faktor paling dominan terhadap kejadian stunting. BBLR merupakan salah satu faktor yang dapat mempengaruhi kejadian stunting, karena seringkali terjadi pada masa pertumbuhan janin terutama pada ibu yang belum cukup umur dan kekurangan gizi selama masa kehamilan (Bappenas, 2016).

Penelitian Candra dkk (2017), menunjukkan bahwa BBLR merupakan salah satu faktor yang paling berpengaruh terhadap kejadian stunting selain faktor tinggi ayah dan riwayat berat badan rendah. Keadaan gizi balita dipengaruhi oleh pola asuh keluarga karena balita masih tergantung dalam memenuhi asupan makan dan perawatan kesehatannya. Sementara itu, kualitas makanan dan gizi sangat tergantung pada pola asuh makan anak yang diterapkan oleh keluarga (Martianto dkk, 2015). Peran ibu dalam pengasuhan sangat penting karena merupakan orang terdekat kepada anak. Pemberian makan ibu dapat mempengaruhi tumbuh kembang anak baik secara positif maupun negatif (Fitriana dkk, 2015).

\section{Metode}

Jenis penelitian ini adalah penelitian kuantitatif dengan korelasi dengan pendekatan cross sectional yang merupakan penelitian yang menekankan pada waktu pengukuran observasi data variabel independen dan dependen di nilai hanya satu kali pada satu saat, menggunakan lembar data demografi dan lembar kuesioner. Penelitian ini dilaksanakan di Desa Je'nemadinging wilayah kerja Puskesmas Paccellekang Kabupaten Gowa.

\section{Hasil dan Pembahasan}

Beberapa gambaran karakteristik responden ditampilkan di bawah ini juga ditampilkan tabel distribusi frekuensinya. 
Tabel 4.1

Distribusi Frekuensi Responden

Berdasarkan Umur Ibu Di Wilayah Kerja

Puskesmas Paccellekang Kabupaten

Gowa

\begin{tabular}{ccc}
\hline Umur & Frekuensi (f) & (\%) \\
\hline $20-30$ & 34 & $55.7 \%$ \\
$31-40$ & 20 & $32.8 \%$ \\
$41-50$ & 7 & $11.5 \%$ \\
\hline Jumlah & 61 & $100 \%$ \\
\hline
\end{tabular}

Sumber data primer 2020

Berdasarkan tabel 4.1 Berdasarkan tabel 4.1 menunjukkan bahwa yang paling banyak yaitu Umur 20-30 sebanyak 34 $(55.7 \%)$ responden dan terendah yaitu tingkat 41-50 sebanyak $7 \quad(11.5 \%)$ responden.

Tabel 4.2

Distribusi Frekuensi Responden

Berdasarkan Pendidikan ibu Di Wilayah Kerja Puskesmas Paccellekang Kabupaten Gowa

Pendidikan Frekuensi $(\%)$

(f)

\begin{tabular}{|c|c|c|}
\hline SMA & 35 & $\begin{array}{c}57.4 \\
\%\end{array}$ \\
\hline SMP & 22 & $\begin{array}{c}36.1 \\
\%\end{array}$ \\
\hline SD & 4 & $6.6 \%$ \\
\hline Jumlah & 61 & $100 \%$ \\
\hline $\begin{array}{l}\text { Sumber data prim } \\
\text { Berdasarkan tabe } \\
4.2 \text { menunjukka } \\
\text { banyak yaitu } \\
\text { sebanyak } 35 \\
\text { terendah yaitu } \\
(6.6 \%) \text { responden. }\end{array}$ & $\begin{array}{l}\text { mer } 2020 \\
\text { el } 4.2 \text { Berdas } \\
\text { an bahwa y } \\
\text { Pendidikan t } \\
\text { (57.4\%) resp } \\
\text { tingkat SD } \\
\text { l. }\end{array}$ & $\begin{array}{l}\text { sarkan tabe } \\
\text { yang palin } \\
\text { tingkat SM } \\
\text { ponden dal } \\
\text { sebanyak }\end{array}$ \\
\hline
\end{tabular}

\section{a. Analisa Univariat}

Tabel 4.3

Distribusi Frekuensi Kejadian Stunting

Pada Anak Usia 12 - 24 Bulan Di Wilayah Kerja Puskesmas Paccellekang Kabupaten Gowa

\begin{tabular}{lcc}
\hline $\begin{array}{c}\text { Kejadian } \\
\text { Stunting }\end{array}$ & Frekuensi & (\%) \\
\hline Tidak terjadi & 43 & $70.5 \%$ \\
Terjadi & 18 & $29.5 \%$ \\
\hline Jumlah & 61 & $100 \%$ \\
\hline
\end{tabular}

\section{Sumber data primer 2020}

Berdasarkan tabel 4.3 diatas maka dapat dilihat bahwa dari 61 responden yang diteliti ditemukan mayoritas Tidak terjadi , yaitu sebanyak 43 responden (70.5\%)

Tabel 4.4

Distribusi Frekuensi Pola Asuh Ibu

Di Desa Je'ne Madinging Kecamatan Pattallassang Kabupaten Gowa

Pola Asuh
Ibu Frekuensi (\%)

\begin{tabular}{lcc}
\hline Baik & 45 & $73.8 \%$ \\
Tidak Baik & 16 & $26.2 \%$ \\
\hline Jumlah & 61 & $100.0 \%$ \\
\hline Sumber data primer 2020
\end{tabular}

Sumber data primer 2020

Berdasarkan tabel 4.4 diatas maka dapat dilihat bahwa dari 61 responden yang diteliti ditemukan dengan pola asuh ibu mayoritas baik, yaitu sebanyak 45 responden $(73.8 \%)$. 


\section{b. Analisa Bivariat}

Tabel 4.5

Hubungan Pola Asuh Ibu dengan Kejadian Stunting Pada Anak Usia 12 - 24 Bulan di Wilayah kerja Puskesmas Paccellekang Kabupaten Gowa

\begin{tabular}{|c|c|c|c|c|c|c|c|}
\hline \multirow{3}{*}{$\begin{array}{c}\text { Pola } \\
\text { Asuh } \\
\text { lbu }\end{array}$} & \multicolumn{4}{|c|}{ Kejadian Stunting } & \multirow{2}{*}{\multicolumn{2}{|c|}{ Jumlah }} & \multirow{2}{*}{$\begin{array}{c}\text { Uji } \\
\text { statist } \\
\text { ik }\end{array}$} \\
\hline & \multicolumn{2}{|c|}{$\begin{array}{l}\text { Tidak } \\
\text { terjadi }\end{array}$} & \multicolumn{2}{|c|}{ Terjadi } & & & \\
\hline & $\mathrm{F}$ & $\%$ & $f$ & $\%$ & $\mathrm{~F}$ & $\%$ & $\begin{array}{c}p- \\
\text { value }\end{array}$ \\
\hline Baik & 39 & $\begin{array}{c}63.9 \\
\%\end{array}$ & 6 & $9.8 \%$ & 45 & $\begin{array}{l}73 . \\
8 \%\end{array}$ & \\
\hline $\begin{array}{l}\text { Tidak } \\
\text { Baik }\end{array}$ & 4 & $6.6 \%$ & $\begin{array}{l}1 \\
2\end{array}$ & $\begin{array}{c}19.7 \\
\%\end{array}$ & 16 & $\begin{array}{l}26 . \\
2 \%\end{array}$ & 0.000 \\
\hline Total & 24 & $\begin{array}{c}70.5 \\
\%\end{array}$ & $\begin{array}{l}2 \\
7\end{array}$ & $\begin{array}{c}29.5 \\
\%\end{array}$ & 61 & $\begin{array}{c}100 \\
.0 \\
\%\end{array}$ & \\
\hline
\end{tabular}

Sumber: Data Primer diolah Tahun 2020

Berdasarkan tabel 4.5 diatas menunjukkan, distribusi Pola Asuh Ibu dengan kejadian stunting pada Pada Anak Usia 12 - 24 bulan di Wilayah kerja Puskesmas Paccellekang Kabupaten Gowa, menunjukkan hasil dari 61 responden terdapat Pola Asuh Baik dengan kejadian Stunting sebanyak 45 orang (73.8 \%) dimana 39 (63.9\%) responden yang tidak terjadi Stunting dan 6 responden $(9.8 \%)$ yang terjadi Stunting. Pada Pola Asuh Ibu yang tidak baik terdapat dengan kejadian Stunting sebanyak 16 (26.2 \%) dimana 4 $(6.6 \%)$ responden yang tidak terjadi stunting dan responden yang terjadi stunting sebanyak 12 (19.7\%). Dari hasil uji statistik menunjukan hasil signifikan dengan $P$ value $=0.000$ dengan tingkat kemaknaan $\alpha=0.05$. Hasil ini menunjukkan bahwa $\mathrm{Ha}$ diterima, yang berarti ada hubungan yang bermakna antara Pola Asuh Ibu dengan kejadian stunting

\section{Simpulan}

1. Berdasarkan dari hasil penelitian yang telah dilakukan mengenai hubungan pola asuh anak usia 12 24 bulan di posyandu desa Je'nemadinging di Wilayah Kerja Puskesmas Paccellekang Kecamatan Pattallassang Kabupaten Gowa, maka dapat disimpulkan bahwa terdapat hubungan yang signifikan antara hubungan distribusi Pola Asuh Ibu dengan kejadian stunting pada Pada Anak Usia 12 - 24 Bulan di Wilayah kerja Puskesmas Paccellekang Kabupaten Gowa, menunjukkan hasil dari 61 responden terdapat Pola Asuh Baik dengan kejadian Stunting sebanyak 45 orang $(73.8 \%)$ dimana 39 (63.9 $\%$ responden yang tidak terjadi Stunting dan 6 responden $(9.8 \%)$ yang terjadi Stunting. Pada Pola Asuh Ibu yang tidak baik terdapat dengan kejadian Stunting sebanyak $16 \quad(26.2 \%)$ dimana 4 (6.6\%) responden yang tidak terjadi stunting dan responden yang terjadi stunting sebanyak 12 (19.7 \%). Dari hasil uji statistik menunjukan hasil signifikan dengan $P$ value $=0.000$ dengan tingkat kemaknaan $\alpha=0.05$. Hasil ini menunjukkan bahwa Ha diterima, yang berarti ada hubungan yang bermakna antara Pola Asuh Ibu dengan kejadian stunting.

2. Bagi Pelayanan Keperawatan Diharapkan penelitian ini dapat berguna sebagai masukan dan bahan bacaan untuk meningkatkan pengetahuan tentang Pola Asuh Ibu dalam meningkatkan Kesehatan anak dalam mencegah kejadian stunting..

3. Bagi perkembangan ilmu keperawatan menambah pengetahuan dan pengalaman dalam penelitian keperawatan semoga dapat diaplikasikan pada saat memberikan pelayanan asuhan keperawatan baik di komunitas, Puskesmas maupun Rumah sakit. 
4. Bagi Riset Keperawatan

Hasil penelitian ini diharapkan dapat menjadi salah satu sumber bahan bacaan dan pembanding bagi peneliti selanjutnya untuk mengembangkan penelitian lebih luas dengan meneliti faktor-faktor lain yang dapat berhubungan dengan kejadian Stunting, Sehingga dapat menekan laju angka kejadian stunting utamanya di Kabupaten Gowa

\section{Daftar Pustaka}

Al kahfi., (2015). Gambaran Pola Asuh Pada Baduta Stunting Usia 13-24 Bulan Di Wilayah Kerja Puskesmas Neglasari Kota Tangerang Tahun 2015. Diakses 27 Desember 2019.

Amalia, H dan Mardiana. (2016). Hubungan Pola Asuh Gizi Ibu dengan Status Gizi Balita Di Wilayah Kerja Puskesmas Lamper Tengah Kota Semarang. Diperoleh dari : file: / / D:/jurnal\%201/11745-

Article\%20Text-36444-1-10-20171027.pdf. Diakses 08 Januari 2020.

Eka. (2019). Hubungan Pola Asuh Orangtua terhadap Kejadian Stunting pada Balita Usia 24-59 Bulan di Desa Singakerta Kecamatan Ubud Gianyar. Diperoleh dari: http://repository.poltekkes-

denpasar.ac.id/2356/10/Lampiran.pdf.

Diakses 23 Mei 2020.

Hardiyanti, R. (2019). Hubungan Pola Asuh Ibu dengan Kejadian Stunting pada Anak Usia 24 - 59 Bulan Di Kecamatan Jelbuk Kabupaten Jember. Diperoleh dari : file:///D:/Rena\%20Hardianty\%20\%20152010101099-.pdf. Diakses 28 Desember 2019.

Juliana, U. (2018). Hubungan Pola Asuh Orang Tua Dengan Kejadian Stunting Pada Balita Di Paud Al Fitrah Kecamatan Sei Rampah Kabupaten Serdang Bedagai Tahun 2018. Diperoleh dari : file:///D:/jurnal\%201/Skripsi.pdf. Diakses 08 Januari 2020.
Kementrian Kesehatan. (2017). 100 Kabupaten/Kota Prioritas untuk Intervensi AnakKerdil(Stunting).Diperolehdari:file:// /D:/jurnal\%201/Buku\%20Ringkasan\%20Stun ting.pdf . Jakarta Pusat. Di akses 03 Januari 2020.

Larasati, N. (2017). Faktor-Faktor Yang Berhubungan Dengan Kejadian Stunting Pada Balita Usia 25-59 Bulan Di Posyandu Wilayah Puskesmas Wonosari li Tahun 2017. Diperoleh dari :

file:///D: / jurnal\%201/SKRIPSI\%20NADIA.p df. Diakses 07 Januari 2020.

Lauku. (2017). Faktor-Faktor Yang Berhubungan Dengan Rencana Pemilihan Penolong Persalinan. Diperoleh dari: http: / / repository. poltekkes-

kdi.ac.id/17/1/LINJULIASTINI\%20A.\%20LAU KU\%20PDF.pdf. Diakses 29 Juni 2020.

Lestari, W. dkk. (2018). Stunting : Studi Konstruksi Sosial Masyarakat Perdesaan Dan Perkotaan Terkait Gizi Dan Pola Pengasuhan Balita Di Kabupaten Jember. Diperoleh dari

file: / / D: / jurnal\%201/985-2799-2-PB.pdf. Diakses 08 Januari 2020.

Notoatmodjo. (2018). Metode dan Teknik Sampling. Konsep dan Penerapan Metodologi Penelitian Ilmu Keperawatan. Salemba Medika: Jakarta.

Nurmalasari, Y. dkk. (2019). Pola Asuh Ibu Dengan Angka Kejadian Stunting Balita Usia 6-59 Bulan. Diperoleh dari : file:///D:/1760-6009-1-PB.pdf. Diakses 29 Juni 2020.

Nursalam. (2014). Manajemen Keperawatan dan Teori Aplikasi dalam Praktik Keperawatan Profesional Edisi 4. Diperoleh dari:

http://ners.unair.ac.id/materikuliah/0\%2 OBUKU\%20MANAJEMEN-

MAK\%20165\%20197.pdf. Diakses 29 Juni 2020. 
Nursalam. (2016). Metodologi Penelitian Ilmu Keperawatan. Jakarta: Salemba Medika.

Rahayu, A. (2018). Study Guide-Stunting Dan Upaya Pencegahannya Bagi Mahasiswa Kesehatan Masyarakat. Diperoleh dari : file:///D:/jurnal\%201/BUKUREFERENSI-STUDY-GUIDE-

STUNTING_2018.pdf. CV Mine Yogyakarta. Diakses 08 Januari 2020.

Rahmayana. (2014). Hubungan Pola Asuh Ibu Dengan Kejadian Stunting Anak Usia 24-59 Bulan Di Posyandu Asoka li Wilayah Pesisir Kelurahan Barombong Kecamatan Tamalate Kota Makassar Tahun 2014. Diperoleh dari : file:///D:/Rahayana.pdf. Diakses 07 Januari 2020.

Riskesdas. Laporan Hasil Riset Kesehatan Dasar Indonesia Tahun 2017. Jakarta: Departemen Kesehatan RI, 2018.

Sabri, \& Hastono (2014). Statistik Kesehatan. Jakarta: PT. Rajagrafindo.

Sandjojo, P. (2017). Buku Saku Desa dalam Penanganan Stunting. Diperoleh dari : file:///D:/jurnal\%201/Buku_Saku_Stunting _Desa.pdf. Diakses 08 Januari 2020.

Setyawan, B. (2018). Faktor - Faktor Penyebab Stunting Pada Anak Usia Dini. Diperoleh dari

file:///D:/jurnal\%201/Stuntingsahabatpaud.com_.pdf. Kota Bekasi. Diakses 07 Januari 2010.

Sugiyono (2015). Metode Penelitian Kombinasi. Bandung: Alfabeta.

Sugiyono. (2017). Konsep Dan Penerapan Metodologi Penelitian Ilmu Keperawatan . Salemba Medika: Jakarta. Tri, S. dkk. (2018). Hubungan Pemenuhan Kebutuhan Asuh Ibu Terhadap Status Stunting Pada Balita Usia 1-5 Tahun Di Puskesmas X Kabupaten Kubu Raya. Diperoleh dari : file:///D:/jurnal\%201/34335-
75676605789-1-PB.pdf. Diakses 08 Januari 2020.

Trihono, dkk. (2015). Pendek (Stunting) di Indonesia, Masalah dan Solusinya. Diperoleh dari:

file: / / / : /jurnal\%201/Stunting-di-

Indonesia-A5-rev-7.pdf. Lembaga Penerbit Balitbangkes, 2015. Diakses 07 Januari 2020.

Wanti, E. (2019). Gambaran Pola Asuh Ibu Anak Balita Umur 3 - 5 Tahun Yang Stunting Di Desa Sidoarjo li Ramunia Kecamatan Beringin Kabupaten Deli Serdang. Diperoleh dari :

file:///D:/EFRI\%20WANTI\%20LUMBANGAOL .PDF. Diakses 28 Desember 2019.

Yudianti dan Rahmat. (2016). Pola Asuh Dengan Kejadian Stunting Pada Balita Di Kabupaten Polewali Mandar. Diperoleh dari : file:///D:/document.pdf. Diakses 03 Januari 2020. 
Patria Artha Journal of Nursing Science. Vol. 5, No.1, April 2021 